\title{
The Mediating Effect of Empathy on the Relationship between Cultural Intelligence and Intercultural Adaptation in Intercultural Service Encounters*
}

\author{
Lan Lan KONG ${ }^{* *}$, Zhi Qiang MA ${ }^{* * *}$, Sung Ho $\mathbf{J I}^{* * * *}$, Jin $\mathbf{L I}^{* * * * *}$
}

Received: November 02, 2019 Revised: December 11, 2019 Accepted: December 18, 2019

\begin{abstract}
Globalization has led to a dramatic increase in intercultural service encounters between services providers and customers from diverse cultural backgrounds. This paper explores the causal relationship between service employees' cultural intelligence and adaptive sales behavior in intercultural service encounters, and the mediating effect of cognitive and emotional empathy on this relationship. A quantitative survey methodology was utilized to collect data on 341 salespeople at duty-free shops located on Jeju Island, Korea. Data analysis was conducted using SPSS 18 and Amos 18. The results show that cultural intelligence has a significant impact on cognitive empathy, emotional empathy, and adaptive sales behavior. Cognitive empathy has a positive impact on adaptive sales behavior, whereas the relationship between emotional empathy and adaptive sales behavior is not significant. Additionally, cognitive empathy mediates the relationship of cultural intelligence and adaptive sales behavior. This study has useful managerial implications for employee selection, training, and development in service firms engaged in intercultural service encounters. This study extends prior research on intercultural service encounters by exploring the direct impact of cultural intelligence on intercultural adaptation and the mediating effect of empathy, suggesting the presence of a cognitive mechanism that plays a key role in the impact of cultural intelligence on adaptive sales behavior.
\end{abstract}

Keywords: Cultural Intelligence, Empathy, Adaptive Sales Behavior, Intercultural Service Encounters.

JEL Classification Code: M12, M16, M31..

\section{Introduction}

Rapid globalization has led to a dramatic increase in intercultural interactions (Lorenz, Ramsey, Tariq, \& Morrel,

*The study was supported by China Postdoctoral Science Foundation(2017M611743), Research Fund for Philosophy and Social Sciences for Universities in Jiangsu Province (2017SJB1066), and Research Initiation Fund for Senior Professionals of Jiangsu University (2018JDG012).

${ }^{* *}$ First Author and Corresponding Author. Associate Professor, School of Management, Jiangsu University, China [Postal Address: Office No. 1409, School of Management, Jiangsu University, No. 301, Xuefu Road, Jingkou District, Zhenjiang City, Jiangsu Province, 212013, China]. Email: jeju2010@126.com.

${ }^{* * *}$ Professor, School of Management, Jiangsu University, China. Email:mzq@ujs.edu.cn.

${ }^{* * * \star A s s o c i a t e ~ P r o f e s s o r, ~ S c h o o l ~ o f ~ M a n a g e m e n t, ~ J i a n g s u ~ U n i v e r s i t y, ~}$ China.Email: jicpa@hanmail.net.

*****Doctoral Student, College of Economics and Management, International Trade, Chungnam National University, South Korea. Email: cpu82lijin@qq.com.

() Copyright: Korean Distribution Science Association (KODISA)

This is an Open Access article distributed under the terms of the Creative Commons Attribution NonCommercial License (https://creativecommons.org/icenses/by-nc/4.0/) which permits unrestricted noncommercial use, distribution, and reproduction in any medium, provided the original work is properly cited.
2017). According to data from UNWTO (World Tourism Organization), approximately 1,323 million tourists traveled abroad in 2017, spending approximately US $\$ 1,340$ billion. In addition, around 244 million migrants have emigrated from their home countries according to a 2018 World Migration Report produced by IOM (International Organization for Migration). The heavy flow of these two groups has led to a wealth of cultural exchange, which, in turn, has effected change within domestic markets as they no longer serve only domestic customers but foreign customers as well. This change has provided corporations with new business opportunities, but has also introduced new challenges because of the increased presence of cultural differences (Gaur, Sharma, Herjanto, \& Kingshott, 2017). As Berry, Poortinga, Segall, and Dasen (1992) have proposed, people from varied cultural backgrounds present many differences in values, beliefs, expectations, perceptions, experiences, behavior, and habits, and these cultural differences may result in intercultural misunderstandings and failures.

The impact of cultural difference is particularly relevant to the service sectors, which involve a high frequency of face-to- 
face interactions (Lorenz et al., 2017). Customers from diverse cultures may have different levels of consumption, consumer preferences, and service experiences and, therefore, may have different needs (Delpechitre \& Baker, 2017). In such an environment, the success of service encounters may partially rely on the ability of service employees to adapt to the cultural diversity of their customers (Chen, Liu, \& Portnoy, 2012; Hansen, Singh, \& Weibaker, 2011).

In this context, academic researchers have highlighted the importance of service employees' intercultural competence with regard to their service behaviors. Sharma and $\mathrm{Wu}$ (2015) have proposed that service employees with higher intercultural competence possess a greater ability to adapt to other cultures, and to mitigate the negative consequences of cultural distance, in addition to improving the quality of customers' perceived service experiences. Kong, Kim, and Kim (2017) examine the moderating effect of salespersons' motivational cultural intelligence on the causal relationship between empathy and customer-oriented behavior in intercultural sales encounters. Lorenz et al. (2017) focus on the moderating effect of meta-cognitive cultural intelligence on the relationship between perceived cultural differences and service encounter adaptation by introducing the idea of the significant impact that a service employees' cultural intelligence has on their ability to adapt to intercultural service encounters. Both papers focus on the moderating effect of one dimension of cultural intelligence; however, they fail to take into consideration the direct impact of cultural intelligence on intercultural adaptation.

Cultural intelligence (CI) refers to an individual's ability to function effectively in culturally diverse situations, and has four dimensions: cognitive, meta-cognitive, motivational, and behavioral (Ang, Van Dyne, Koh, Ng, Templer, Tay, \& Chandrasekar, 2007). The impact of cultural intelligence on the enhancement of employees' cultural adaptation and task performance has been verified by scholars in the field of organizational management (Ang et al., 2007; Huff, Song, \& Gresch, 2014). These findings provide a basis for studying the direct impact of cultural intelligence on intercultural adaptation in service sectors; however, the psychological mechanisms at work in this relationship have not been examined. That is to say, there is no consideration given to the mediating mechanisms between cultural intelligence and intercultural adaptation.

To address these research gaps, we explore the influence of cultural intelligence on adaptive sales behavior in intercultural service encounters, and use social identity theory to examine the mediating effect of multi-dimensional empathy (cognitive empathy, emotional empathy), ultimately revealing the psychological mechanisms of cultural intelligence and its affect on adaptive behavior.

\section{Literature Review}

\subsection{Cultural Intelligence}

Grounded in the Theory of Multiple Intelligences, CI is thought to be a complementary form of intelligence derived from general intelligence (Earley \& Ang, 2003). With respect to individual intelligence, early studies tended to view intelligence narrowly in academic or cognitive terms. However, since Gardner (1985) proposed the Theory of Multiple Intelligences, there has been growing interest in introducing new kinds of intelligence in the 'real world' rather than the classroom. According to the Theory of Multiple Intelligences, individuals have types of intelligence that are mutually independent but in interaction with one another (Jeon, 2001). Some types of intelligence can be grouped into specific domains, such as social intelligence (SI), which focuses on social relationships (Thorndike \& Stein, 1937); emotional intelligence (EI), which is related to the management of emotions (Mayer \& Salovey, 1993); and practical intelligence, which takes into account real-world skills (Sternberg, 2002). CI emphasizes a particular domain, intercultural background, focusing on the cultural aspects of interaction (Earley \& Ang, 2003).

In this sense, $\mathrm{CI}$ is both similar to and different from SI and EI. CI is similar to SI and EI because it is a set of capabilities rather than an array of preferred ways of behaving (Mayer, Caruso, \& Salovey, 1999). However, CI is also distinct from both SI and EI. Crowne (2009) argued that SI is a broader construct that incorporates EI and CI. EI comprises the ability to deal with personal emotions independent of cultural context (Ang et al., 2007), whereas CI is considered to represent the ability to perceive and adapt to cultural interactions not related to emotions (Crowne, 2009). However, EI and CI are aspects of intelligence that are necessary for successful social interactions (Crowne, 2009). Furthermore, unlike other types of intelligence, $\mathrm{CI}$ is characterized by cultural diversity.

$\mathrm{CI}$ is a multi-dimensional construct that includes cognitive, meta-cognitive, motivational, and behavioral components (Earley \& Ang, 2003; Ang et al., 2007; Ang \& Van Dyne, 2008). Cognitive CI refers to an individual's level of knowledge about different cultures, which includes their knowledge of economic, legal, social and religious systems, as well as marriage and language (Ang et al., 2007). Those with high cognitive CI are expected to be aware of similarities and differences across cultures (Brislin, Worthley, \& Macnab, 2006). Compared with cognitive CI, meta-cognitive CI is a higher-order cognitive process used by individuals to acquire and process cultural knowledge during intercultural interactions (Earley \& Ang, 2003; Ang \& Van Dyne, 2008). Meta-cognitive CI involves analyzing and adjusting cultural knowledge, as 
well as monitoring its accuracy when with people from different cultural backgrounds (Moon, 2010). Motivational CI reflects one's ability to direct effort and energy to learning about, and functioning in, intercultural settings (Ang et al., 2007). Motivational CI includes one's intrinsic interest in interacting with people from different cultures as well as the self-confidence to deal with people from and situations involving different cultures (Ang \& Van Dyne, 2008; Groves, Feyerherm, \& Gu, 2015). Finally, behavioral CI represents an individual's capability to deploy appropriate verbal and nonverbal actions in intercultural interactions (Ang et al., 2007; Ang \& Van Dyne, 2008). Those with high behavioral $\mathrm{CI}$ are able to exhibit flexibility in different cultural situations, such as by adapting their words, tone, gestures, and facial expressions (Ang, Van Dyne, \& Koh, 2006). These four components of CI have different facets in functioning and managing effectively in intercultural settings; together, they form an aggregate CI (Ang et al., 2007; Ang \& Van Dyne, 2008).

\subsection{Cultural Intelligence and Adaptive Sales Be havior}

Adaptive sales behaviors (ASBs) refer to adjustments in behavior during or across all customer interactions based on perceptions of the sales situation at hand (Weitz, Sujan, \& Sujan, 1986). Salespeople with a high level of adaptive selling ability are likely to modify their behavior according to consumer needs and preferences, using different sales techniques to adapt to each encounter (Franke \& Park, 2006; Spiro \& Weitz, 1990). The practice of adaptive selling is key to success in the personal sales domain, as it increases salesworker performance (Franke \& Park, 2006), improves consumer satisfaction and loyalty, and promotes the establishment of long-term relationships with customers (Baldauf \& Cravens, 2002).

Weitz and colleagues have suggested that a salesperson's specific capabilities influence the effectiveness of adaptive selling (Weitz et al., 1986). Spiro and Weitz (1990) and propose six specific types of ability: recognizing different selling approaches for different sales situations; having a knowledge structure that enables the development of sales strategies appropriate for different situations; collecting information about sales situations to facilitate adaptation; having confidence in using appropriate sales approaches; having confidence to alter the sales approach during a customer interaction; and implementing different approaches in various situations. That is, to practice adaptive selling effectively, salespeople must possess multiple attributes: cognitive capability, which includes the first three factors; motivational capability, which relates to the fourth and fifth factors; and behavioral capability, which pertains to the sixth factor.
Accordingly, a salesperson's cultural intelligence (i.e., the individual's capability to function effectively in culturally diverse situations (Earley \& Ang, 2003)) directly impacts the presence of adaptive selling in intercultural sales situations. As previously described, cultural intelligence consists of cognitive, meta-cognitive, motivational, and behavioral components (Ang et al., 2007). High levels of cognitive and meta-cognitive ability enable salespeople to recognize cultural considerations in different sales situations and utilize this information to adapt their behavior accordingly. Motivational CI can stimulate a salesperson's self-confidence and boost their employment of different sales approaches, as well as their ability to adapt them appropriately. Finally, behavioral CI leads directly to the adoption and use of selling strategies. Thus, although prior studies have not empirically demonstrated the relationship between CI and ASB from a service sector perspective, we can infer that CI has a positive influence on ASB.

Additionally, previous research on the relationship of CI and adaptive outcomes supports the positive influence of CI on ASB. For instance, Ang et al. (2007) find that, in intercultural working environments, the $\mathrm{CI}$ of international workers positively influences cultural adaptation. Sahin and Gürbüz (2014) find that CI is a significant predictor of adaptive performance, which refers to an individual's capacity to deal with novel environments. These findings empirically demonstrate the importance of CI for adaptive performance. Thus, we hypothesize that:

Hypothesis 1: Cultural intelligence has a positive effect on adaptive sales behavior.

\subsection{The Mediating Effect of Empathy}

Empathy, which originates from the German term 'einfühlung' introduced by Lipps (1907), means 'feeling into' (McBane, 1995). In the service sector, empathy is considered important in service encounters and is recognized as a twodimensional construct from cognitive and affective perspectives (Bettencourt, Gwinner, \& Meuter, 2001; Itani \& Inyang, 2015; McBane, 1995; Widmier, 2002). Following this point of view, we conceptualize empathy as the individuals' responses to the observed experiences of other individuals (Spiro \& Weitz, 1990), which includes cognitive empathy and emotional empathy. Cognitive empathy, which is equivalent to perspective-taking, refers to a cognitive response induced by taking the viewpoint of another and inferring another person's thoughts, feelings, and actions from various cues (Strayer, 1987). Cognitive empathy may occur when one attempts to predict and understand another person's viewpoint (Davis, 1980). In service encounters, service employees who are high in cognitive empathy are better able to recognize the reactions 
of customers, perceive their needs and expectations, and subsequently take appropriate actions (McBane, 1995; Widmier, 2002). Emotional empathy includes affective responses that involve sharing another's affect or feeling (Kerem, Fishman, \& Josselson, 2001). This affective response incorporates concepts such as sympathy, compassion, and tenderness, which reflect emotional warmth and acceptance, without the requirement to experience the identical emotion as another person (Batson \& Shaw, 1991). In service encounters, service employees with high emotional empathy tend to pay attention to customers' emotions, maximize their vicarious enjoyment through customer satisfaction, and be helpful toward customers (Miller, Stiff, \& Ellis, 1988; Widmier, 2002).

Considering the important role of empathy in service encounters, considerable research has empirically investigated behaviors associated with empathy, such as adaptive selling practices (Giacobbe, Crosby, \& Bridges, 2006; Kim, 2014), customer-oriented action (Widmier, 2002), and positive service delivery (Bettencourt, Gwinner, \& Meuter, 2001). However, most of this previous research has focused on the consequences of empathy, and relatively little work has explored its antecedent factors. To address this gap, we propose an individual character, CI, as a causative antecedent factor for empathy. CI is an individual's ability to function well in culturally diverse situations (Earley \& Ang, 2003). Sharma, Tam, and Kim (2012) suggested that, in ICSES, service employees with higher cultural competence are more able to empathize with foreigner customers because of their understanding of foreign languages and cultures. Thus, the evidence seems to suggest that empathy for foreign customers is influenced by service employees' cultural capability.

Regarding the relationship between $\mathrm{CI}$ and the dimensions of empathy (i.e., cognitive empathy and emotional empathy), Joseph and Newman (2010) investigated the manner in which cognitive ability strengthens emotional understanding. Kim (2015) demonstrated that the self-soothing ability, which is also considered to be an individual ability, has a positive effect on cognitive intelligence and emotional intelligence. These findings provide grounds for the positive influence of individual ability on cognitive and emotional empathy. Accordingly, service employees with high CI in ICSEs have the ability to analyze cultural information, such as foreign language, facial expression, tone, gesture, and body language. Thus, it is easier for these employees to recognize and infer foreign customers' viewpoints during interactions. Furthermore, because these employees are able to recognize customers' feelings, they tend to share customers' affects or experience vicarious feelings. Despite the potential of CI to facilitate greater cognitive and emotional empathy, few empirical studies have investigated this relationship. Therefore, we formulate the following hypotheses:
Hypothesis 2: Cultural intelligence has a positive effect on cognitive empathy.

Hypothesis 3: Cultural intelligence has a positive effect on emotional empathy.

In personal sales encounters, empathy is a significant predictor of the ability to practice adaptive selling (Spiro \& Weitz, 1990; Widmier, 2002). As Spiro and Weitz (1990) have argued, a salesperson's empathy positively influences adaptive sales behavior because the components of empathy (e.g., perspective-taking and empathetic concern) are positively associated with aspects of adaptive selling, such as perceiving customer needs and collecting situational Several prior studies have focused on the separate roles of the components of empathy (cognitive empathy and emotional empathy) in adaptive selling. Cognitive empathy, which refers to adopting a customer's perspective during interactive encounters, allows salespeople to better understand customer needs and expectations and subsequently engage in appropriate actions (McBane, 1995; Widmier, 2002). Cognitive empathy has been validated as a predictor of ASB by several researchers. Kim (2014) found that salespeople's cognitive empathy facilitates adaptive sales behavior in sales encounters. Similarly, Giacobbe et al. (2006) found that adopting customers' perspectives improves adaptive selling intentions, thereby leading to adaptive sales behavior. Emotional empathy, which involves sharing another person's affect or feelings vicariously (Kerem et al., 2001), increases employees' compassion for customers and enhances their desire to satisfy customer needs through superior service delivery (Bettencourt et al., 2001). Widmier (2002) concluded that salespeople with high levels of empathy desire to maximize their vicarious enjoyment by satisfying customers; they are therefore more customer-oriented than those with low levels of empathy. Kim (2014) found that high levels of emotional empathy facilitate adaptive sales behavior in sales situations. Therefore, we hypothesize the following relationship: information to facilitate behavioral adaptation.

Hypothesis 4: Cognitive empathy has a positive effect on adaptive sales behavior.

Hypothesis 5: Emotional empathy has a positive effect on adaptive sales behavior.

According to social identity theory, individuals tend to classify themselves into specific social groups. Through this classification process, individuals who are similar to themselves are classified as inner groups, while those who are different are classified as outer groups (Tajfel \& Turner, 1979). Individuals tend to establish emotional 
connections with inner groups and thus act in their favor (Hogg \& Terry, 2000; Solnet, 2006).

From this point of view, service employees with high cultural intelligence are more likely to regard foreign customers as inner group numbers and generate positive emotional resonance and empathy. Ashforth and Mael (1989) proposed that group familiarity and group homogeneity can promote the formation of individual social identity. Bloom (2017) also believed that the evolutionary nature of empathy makes it easier for individuals to empathize with inner groups. Service employees with higher cultural intelligence, who are likely to understand foreign customers' language, habits, gestures and other cultural characteristics, can reduce perceived cultural differences and reduce psychological distance with foreign customers. Regarding foreign customers as the same group members allows service employees to share the perspective of the consumers, empathize with their feelings, and understand their needs and expectations. By adjusting their sales methods, they can provide customers with increasingly satisfactory experiences.

Hypothesis 6: Cognitive empathy mediates the relationship of cultural intelligence and adaptive sales behavior.

Hypothesis 7: Emotional empathy mediates the relationship of cultural intelligence and adaptive sales behavior.

\section{Methodology}

\subsection{Measures}

We used a quantitative survey methodology to test the hypotheses. Measures for all constructs were adapted from prior studies. Because the survey respondents were Korean and some measures were originally developed in English, we translated the English measures into Korean using Brislin's (1970) translation procedures. All instruments used sevenpoint Likert scales (from $1=$ strongly disagree to $7=$ strongly agree).

We used the 20 items developed by Ang et al. (2007) to measure cultural intelligence. This scale is composed of four sub-constructs: cognitive, meta-cognitive, motivational, and behavioral intelligence. Empathy was evaluated with eight items adapted from Davis (1980) and Kim (2006) and included two sub-dimensions: cognitive empathy and emotional empathy. To measure adaptive sales behavior, we used three items from Spiro and Weitz (1990).

\subsection{Sample and Data Collection}

We surveyed Korean salespeople working at duty-free shops on Jeju Island. As a tourism-based region, Jeju Island has attracted a large number of foreign tourists since being designated as an international free city in 2002. Owing to this phenomenon, intercultural encounters between service employees and customers from different cultures have become commonplace. Compared to other service employees, salespeople working in duty-free shops have more frequent intercultural interactions, as over $90 \%$ of their total customers are from foreign countries. Additionally, regular professional training programs for salespeople help cultivate cultural intelligence.

The questionnaires were distributed to the managers or salespeople at select duty-free shops. Out of the 400 questionnaires distributed, 375 were collected. After deleting invalid questionnaires, we used a total of 341 for our analysis, which represents an $85.3 \%$ validity rate. The demographic characteristics of respondents are summarized in Table 1.

Table 1: Demographic characteristics of sample

\begin{tabular}{|c|c|c|}
\hline Demographic profile & frequency & $(\%)$ \\
\hline \multicolumn{3}{|l|}{ Gender } \\
\hline Male & 56 & 16.4 \\
\hline Female & 285 & 83.6 \\
\hline \multicolumn{3}{|l|}{ Age } \\
\hline 29 and under & 149 & 43.7 \\
\hline $30-39$ & 135 & 39.6 \\
\hline 40 and above & 57 & 16.2 \\
\hline \multicolumn{3}{|c|}{ Educational level } \\
\hline High school graduation and under & 82 & 24.0 \\
\hline University graduate & 250 & 73.4 \\
\hline Postgraduate and above & 9 & 2.6 \\
\hline \multicolumn{3}{|c|}{ Type of merchandise } \\
\hline Cosmetics, perfume, etc. & 64 & 18.8 \\
\hline Clothing & 80 & 23.5 \\
\hline Watches, jewelry, accessories & 44 & 12.9 \\
\hline Electronic goods & 37 & 10.9 \\
\hline Tobacco and Liquor & 29 & 8.5 \\
\hline Leather products (bags, belts, shoes) & 52 & 15.2 \\
\hline Local products & 35 & 10.3 \\
\hline \multicolumn{3}{|c|}{ Job experience with foreign customers } \\
\hline 1year or less & 64 & 18.8 \\
\hline $1-2$ years & 80 & 23.5 \\
\hline 2-3 years & 44 & 12.9 \\
\hline $3-4$ years & 37 & 10.9 \\
\hline $4-5$ years & 29 & 8.5 \\
\hline $5-10$ years & 52 & 15.2 \\
\hline over 10 years & 35 & 10.3 \\
\hline Total & 341 & 100.0 \\
\hline
\end{tabular}




\section{Data Analysis and Findings}

\subsection{Validity and Reliability of Multidimensional Cultural Intelligence}

We conducted statistical analysis of the questionnaire data, beginning with an evaluation of the validity and reliability of multidimensional cultural intelligence. Owing to the relative newness of the concept of cultural intelligence, empirical research on cultural intelligence is limited in scope (Ang et al., 2007). Accordingly, we conducted exploratory factor analysis using the principal-components method and varimax rotation. We assessed the results using specific minimum standards: eigenvalues greater than 1, communality scores greater than 0.4, and factor loadings greater than 0.5 .

As shown in Table 2, the exploratory factor analysis revealed that all items loaded on four constructs: cognitive, meta-cognitive, motivational, and behavioral cultural intelligence. All loading coefficients were greater than 0.5 after eliminating one item (behavioral cultural intelligence) because of an insufficient loading coefficient. These four constructs explained $70.57 \%$ of the variance. We also tested the internal reliability of the four dimensions of cultural intelligence by calculating Cronbach's alpha for each dimension. The reliability of each of the four dimensions is satisfactory beyond the standard of 0.7 .

Table 2: Exploratory Factor Analysis and Reliability of Cultural Intelligence

\begin{tabular}{|c|c|c|c|c|c|}
\hline Construct and Measures & Commonality & 1 & 2 & 3 & 4 \\
\hline \multicolumn{6}{|l|}{ Cognitive $C I$ (Eigen Value $=4.051$, Variance $=21.32 \%$, Cronbach's alpha $=0.895)$} \\
\hline [1] I know the legal and economic systems of other cultures. & .669 & .764 & .103 & .264 & .070 \\
\hline [2] I know the rules(e.g., vocabulary, grammar) of other languages. & .563 & .604 & .218 & .296 & .251 \\
\hline [3] I know the cultural values and religious beliefs of other cultures. & .759 & .836 & .132 & .183 & .099 \\
\hline [4] I know the marriage systems of other cultures. & .749 & .797 & .150 & .278 & .116 \\
\hline [5] I know the arts and crafts of other cultures. & .687 & .770 & .196 & .235 & -.005 \\
\hline [6] I know the rules for expressing nonverbal behaviors in other cultures. & .601 & .678 & .299 & .184 & .135 \\
\hline \multicolumn{6}{|l|}{ Meta-cognitive CI (Eigen Value $=3.526$, Variance $=18.56 \%$, Cronbach's alpha $=0.922$ ) } \\
\hline $\begin{array}{l}\text { [1] I am conscious of the cultural knowledge I use when interacting with people with } \\
\text { different cultural backgrounds. }\end{array}$ & .824 & .363 & .221 & .777 & .197 \\
\hline $\begin{array}{l}\text { [2] I adjust my cultural knowledge as I interact with people from a culture that is unfamiliar } \\
\text { to me. }\end{array}$ & .804 & .300 & .261 & .792 & .139 \\
\hline [3] I am conscious of the cultural knowledge I apply to cross-cultural interactions. & .851 & .364 & .169 & .824 & .108 \\
\hline $\begin{array}{l}\text { [4] I check the accuracy of my cultural knowledge as I interact with people from different } \\
\text { cultures. }\end{array}$ & .768 & .349 & .267 & .752 & .101 \\
\hline \multicolumn{6}{|l|}{ Motivational CI (Eigen Value $=3.083$, Variance $=16.23 \%$, Cronbach's alpha $=0.895)$} \\
\hline [1] I enjoy interacting with people from different cultures. & .742 & .151 & .795 & .225 & .190 \\
\hline [2] I am confident that I can socialize with locals in a culture that is unfamiliar to me. & .736 & .272 & .764 & .259 & .105 \\
\hline [3] I am sure I can deal with the stresses of adjusting to a culture that is new to me. & .651 & .177 & .778 & .112 & .046 \\
\hline [4] I enjoy living in cultures that are unfamiliar to me. & .746 & .147 & .781 & .124 & .314 \\
\hline [5] I am confident that I can get accustomed to the shopping conditions in a different culture. & .737 & .218 & .728 & .213 & .338 \\
\hline \multicolumn{6}{|l|}{ Behavioral CI (Eigen Value $=2.747$, Variance $=14.46 \%$, Cronbach's alpha $=0.799)$} \\
\hline $\begin{array}{l}\text { [1] I change my verbal behavior (e.g., accent, tone) when a cross-culture interaction requires } \\
\text { it. }\end{array}$ & .514 & .042 & .205 & .172 & .664 \\
\hline [2] I vary the rate of my speaking when a cross-cultural situation requires it. & .591 & .133 & .074 & .172 & .734 \\
\hline [3] I change my nonverbal behavior when a cross-cultural situation requires it. & .701 & .146 & .123 & .015 & .815 \\
\hline [4] I alter my facial expressions when a cross-cultural interaction requires it. & .715 & .050 & .245 & .032 & .807 \\
\hline
\end{tabular}

\subsection{Analysis of the Measurement Model}

We examined the measurement model, which contained all the constructs involved in this study, using confirmatory factor analysis. Before conducting confirmatory factor analysis, we performed item parceling of cultural intelligence for two reasons. First, the aim of the present study was to explore the influence of cultural intelligence on dependent variables. Therefore, we focused on the overall effect of cultural intelligence. The second reason 
was related to the fit of the structural equation model. In such models, the inclusion of too many observed variables within a latent variable can reduce the model's degree of simplicity and goodness-of-fit (Kim, 2014). In this study, cultural intelligence includes 20 observed variables, which may reduce the suitability and simplicity of the research model.

The results of our measurement model analysis are summarized in Table 3. We used the maximum likelihood method to perform confirmatory factor analysis and evaluated the results with output indices, such as normed chisquare, goodness-of-fit index (GFI) (standard: above 0.9), comparative fit index (CFI) (standard: above 0.9), normed fit index (NFI) (standard: above 0.9), and root mean square error of approximation (RMSEA) (standard: between 0.05 and 0.08) (Hu \& Bentler, 1999). After eliminating one emotional empathy factor because of insufficient loading coefficients, the measurement model was well-fitted, with the standardized factor loadings of all observed variables greater than 0.5 .The fit indices were also acceptable $(\chi 2=198.908, \mathrm{df}=68, \mathrm{p}<0.001, \chi 2 / \mathrm{df}=2.925$, $\mathrm{GFI}=0.923, \mathrm{CFI}=0.960, \mathrm{NFI}=0.941, \mathrm{RMSEA}=0.075)$.

Table 3: Measurement Model Evaluation

\begin{tabular}{|c|c|}
\hline Construct and Measures & Standard Factor loadings \\
\hline \multicolumn{2}{|l|}{ Cultural intelligence $(A V E=0.541, C R=0.825$, Cronbach's alpha $=0.790)$} \\
\hline [1] cognitive $\mathrm{CI}$ & 0.740 \\
\hline [2] meta-cognitive CI & 0.738 \\
\hline [3] motivational CI & 0.749 \\
\hline [4] behavioral CI & 0.630 \\
\hline \multicolumn{2}{|l|}{ Cognitive empathy $(A V E=0.745, C R=0.921$, Cronbach's alpha $=0.932)$} \\
\hline [1] I try to understand my customers' behaviors by "putting myself in their shoes". & 0.838 \\
\hline [2] I try to understand my customers' stance. & 0.872 \\
\hline [3] I try to understand my customers better by imagining how things look from their perspective. & 0.905 \\
\hline [4] I look at the situation from my customer's perspective. & 0.885 \\
\hline \multicolumn{2}{|l|}{ Emotional empathy $(A V E=0.650, C R=0.847$, Cronbach's alpha $=0.848)$} \\
\hline [1] I try to experience the unpleasant emotion that customers show. & 0.812 \\
\hline [2] I am concerned about my customers' difficulties. & 0.913 \\
\hline [3] I share my customers' pain. & 0.809 \\
\hline \multicolumn{2}{|l|}{ Adaptive sales behavior (AVE $=0.696, C R=0.873$, Cronbach's alpha $=0.900)$} \\
\hline [1] I am very flexible in the selling approach I use. & 0.853 \\
\hline [2] I vary my sales style from situation to situation. & 0.899 \\
\hline [3] It is easy for me to modify my sales presentation if the situation calls for it. & 0.851 \\
\hline
\end{tabular}

Further, to examine the convergent validity of construct variables, we calculated the average variance extracted (AVE) based on the factor loading of the indicators associated with each construct (Gerbing \& Anderson, 1988).

All AVE values ranged from 0.541 to 0.745 , which were well above the threshold of 0.5 . We also examined the discriminant validity by comparing the square root of the
AVE for each construct against the correlations between constructs (Fornell \& Larcker, 1981). The results showed that the smallest square root of AVE (square root of AVE of $\mathrm{CI}=0.745$ ) was higher than the strongest correlation $(\mathrm{r}=0.721)$ between cognitive empathy and emotional empathy (Table 4).

Table 4: Descriptive Statistics and Correlation Analysis

\begin{tabular}{|c|c|c|c|c|c|}
\hline Construct & Mean & 1 & 2 & 3 & 4 \\
\hline Cultural intelligence(1) & 4.401 & 0.745 & & & \\
\hline Cognitive empathy(2) & 4.933 & $.551 * *$ & 0.863 & & \\
\hline Emotional empathy(3) & 4.490 & $.496 * *$ & $.721 * *$ & 0.806 & \\
\hline Adaptive sales behavior(4) & 5.209 & $.405 * *$ & $.533 * *$ & $.455^{* *}$ & .834 \\
\hline
\end{tabular}

Note: $\mathrm{N}=341,{ }^{*} \mathrm{p}<.05, * * \mathrm{p}<.01, * * * \mathrm{p}<.001$

Thus, the discriminant validities of all variables were confirmed. Furthermore, we tested the internal consistency for all constructs using Cronbach's alpha and composite reliability (CR). All constructs demonstrated strong 
reliability as all Cronbach's alpha and CR values were greater than 0.7 . We also found significant positive correlations between all variables.

\subsection{Path Analysis of Structural Model}

Before testing our hypotheses, we investigated whether a better-fitting model existed by evaluating competing comparative models that included the same constructs but differed in their number of paths (Table 5).

The initial research model is a partial mediation model that includes the causal relationship between cultural intelligence and adaptive sales behavior, and the mediating effect of cognitive and emotional empathy on this relationship. Comparative model 1 eliminated the path of cultural intelligence and adaptive sales behavior. Comparative model 2 included the paths of cognitive empathy and emotional empathy to evaluate the relationship between these variables, as suggested by Kim (2006). We compared our initial model to comparative models 1 and 2, and found that comparative model 1 had a relatively poor fit with the initial research model $(\Delta \chi 2=3.935, \mathrm{p}<0.05)$, but comparative model 2 had a superior fit $(\Delta \chi 2=104.028, \mathrm{p}<0.001)$. Thus, we used comparative model 2 to test our hypotheses.

Table 5: Comparison of Structural Models

\begin{tabular}{|c|c|c|c|c|c|c|c|c|c|c|c|c|}
\hline \multirow[b]{2}{*}{ Model } & \multirow[b]{2}{*}{$\chi^{2}$} & \multirow[b]{2}{*}{$\mathbf{p}$} & \multirow[b]{2}{*}{ df } & \multirow[b]{2}{*}{$\chi^{2} / \mathbf{d f}$} & \multirow[b]{2}{*}{ GFI } & \multirow[b]{2}{*}{ CFI } & \multirow[b]{2}{*}{ NFI } & \multirow[b]{2}{*}{ RMSEA } & \multicolumn{4}{|c|}{ Chi-Square Difference } \\
\hline & & & & & & & & & $\begin{array}{c}\text { Compar- } \\
\text { ison }\end{array}$ & $\Delta \chi^{2}$ & $\Delta \mathrm{df}$ & $\mathbf{P}$ \\
\hline Initial model & 302.936 & $<.001$ & 69 & 4.390 & .882 & .929 & .910 & .100 & - & - & - & - \\
\hline Comparative model 1 & 306.871 & $<.001$ & 70 & 4.384 & .880 & .928 & .909 & .100 & IN1-CM1 & 3.935 & 1 & $\mathrm{p}<.05$ \\
\hline Comparative model 2 & 198.908 & $<.001$ & 68 & 2.925 & .923 & .960 & .941 & .075 & IN1-CM2 & 104,028 & 1 & $\mathrm{p}<.001$ \\
\hline
\end{tabular}

Note: $\mathrm{N}=341,{ }^{*} \mathrm{p}<.05, * * \mathrm{p}<.01,{ }^{* * *} \mathrm{p}<.001$

The results of hypothesis verification are as follows. Firstly, in the model excluding mediating variables, the main effect between cultural intelligence and adaptive sales behavior is supported $(S \cdot \beta=0.433, p<0.001)$. Next, in the model including mediating variables, cultural intelligence has significant positive effects with both cognitive empathy $(\mathrm{S} \cdot \beta=0.630, \mathrm{P}<0.001)$ and emotional empathy $(\mathrm{S} \cdot \beta=0.149$, $\mathrm{P}<0.01$ ). And so, hypothesis 2 and 3 are supported. Cognitive empathy has a significant positive impact on adaptive sales behavior ( $\mathrm{S} \cdot \beta=0.407, \mathrm{p}<0.001$ ), supporting $\mathrm{H} 4$. However, we found no significant relationship between emotional empathy and adaptive sales behavior ( $\mathrm{S} \cdot \beta=0.097, \mathrm{p}>0.05$ ). H5 was therefore not supported. In the path of cultural intelligence $\rightarrow$ cognitive empathy $\rightarrow$ adaptive sales behavior, compared with the main effect test result $(S \cdot \beta=0.433$, $\mathrm{p}<0.001$ ), the indirect effect of cultural intelligence and adaptive sales behavior is reduced $(S \cdot \beta=0.151, P<0.05$ ). Through the Sobel $\mathrm{Z}$ test, the $\mathrm{Z}$ value of the path relationship is $4.026(p<0.001)$; therefore, the indirect effect is confirmed, supporting H6. H7 is not supported because it does not satisfy the mediating conditions.

Table 6: The property of Path Analysis

\begin{tabular}{|c|c|c|c|c|c|}
\hline \multicolumn{2}{|r|}{ Path } & $\boldsymbol{\beta}$ & $\mathbf{S} \cdot \boldsymbol{\beta}$ & S.E. & Result \\
\hline $\mathrm{HI}$ & Cultural intelligence $\rightarrow$ Adaptive sales behavior (the main effect) & $.645^{* * *}$ & $.433^{* * *}$ & .094 & Supported \\
\hline & Cultural intelligence $\rightarrow$ Adaptive sales behavior (the indirect effect) & $.213^{*}$ & $.151^{*}$ & .104 & \\
\hline $\mathrm{H} 2$ & Cultural intelligence $\rightarrow$ Cognitive empathy & $.869^{* * *}$ & $.630^{* * *}$ & .086 & Supported \\
\hline $\mathrm{H} 3$ & Cultural intelligence Emotional empathy & $.206^{* *}$ & $.149^{* *}$ & .079 & Supported \\
\hline & Cognitive empathy $\rightarrow$ Emotional empathy & $.680^{* * *}$ & $.677^{* * *}$ & .066 & - \\
\hline $\mathrm{H} 4$ & Cognitive empathy $\rightarrow$ Adaptive sales behavior & $.417^{* * *}$ & $.407^{* * *}$ & .095 & Supported \\
\hline H5 & Emotional empathy $\rightarrow$ Adaptive sales behavior & .099 & .097 & .085 & Not Supported \\
\hline H6 & \multicolumn{4}{|c|}{ Cultural intelligence $\rightarrow$ Cognitive empathy $\rightarrow$ Adaptive sales behavior } & Supported (partial mediation) \\
\hline H7 & \multicolumn{4}{|c|}{ Cultural intelligence $\rightarrow$ Emotional empathy $\rightarrow$ Adaptive sales behavior } & Not Supported \\
\hline
\end{tabular}

Note: $\mathrm{N}=341, * \mathrm{p}<.05, * * \mathrm{p}<.01, * * * \mathrm{p}<.00$ 


\section{Discussion and Conclusions}

In this paper, we explored the causal relationship between service employees' cultural intelligence and adaptive sales behavior, and the mediating effect of empathy on this relationship. The results are as follows. First, we found that cultural intelligence, as an independent variable, can directly affect adaptive sales behavior. The results indicated that service employees' cultural intelligence can promote intercultural adaptation in ICSEs. The findings expand the previous research results (Kong et al., 2017; Lorenz et al., 2017), supporting the applicability of cultural intelligence to intercultural service sectors.

Second, we also found that cultural intelligence could facilitate cognitive and emotional empathy. The results indicate that when service employees in ICSEs have a high level of cultural intelligence, they are more likely to identify with the experiences and feelings of foreign customers. This provides empirical verification of the results of previous studies (Sharma et al., 2012), which have suggested a positive relationship between cultural competence and empathy, and extends our understanding of the influence of $\mathrm{CI}$ on empathy to intercultural interactions.

Third, we revealed the different influences of cognitive empathy and emotional empathy on adaptive sales behavior. We found that cognitive empathy has a positive influence on adaptive sales behavior. This suggests that adopting a customer's viewpoint may facilitate adaptive selling, which is consistent with Giacobbe et al. (2006) and Kim (2014). This result confirms that cognitive empathy enhances adaptive sales behavior in ICSEs.

However, we found no support for a relationship between emotional empathy and adaptive sales behavior, which was inconsistent with the results of previous research (Widmier, 2002; Kim, 2014). One explanation for this discrepancy may be the complexity of intercultural sales situations. Unlike intra-cultural encounters, in ICSEs, salespeople face many new situations beyond the scope of their experience. In such novel situations, even salespeople with high levels of emotional empathy may be unable to identify with their customers and practice adaptive selling. Thus, the positive relationship between emotional empathy and adaptive sales behavior demonstrated by Widmier (2002) and Kim (2014) may apply in intra-cultural contexts but not intercultural contexts. Accordingly, we suggest that cultural context should be considered when studying this relationship.

Fourth, we found a significant relationship between cognitive empathy and emotional empathy, which provides support for Kim (2006). This finding provides a deeper understanding of the casual relationships among the dimensions of empathy. Namely, salespeople in service encounters are more likely to share a customer's affects after analyzing and understanding her/his point of view.
Finally, we explored the mediating effect of cognitive empathy on the relationship between cultural intelligence and adaptive sales behavior. That is to say, cultural intelligence can directly affect adaptive sales behavior, but also indirectly affect adaptive sales behavior through cognitive empathy. This confirms that psychological mechanisms play a key role in the impact of cultural intelligence on adaptive sales behavior. This finding addresses the gap found in previous research, which has failed to consider the mediating mechanisms between cultural intelligence and intercultural adaptation.

\section{Managerial Implications}

In addition to the conceptual contributions discussed above, our findings have managerial implications for service firms that deal with intercultural service encounters. First, managers should be aware that cultural intelligence is an essential attribute in intercultural interactions. As intercultural interactions involve complex encounters between employees and customers from different cultural environments, understanding these cultural environments is very important. Thus, managers should take cultural intelligence into account when recruiting new employees. Moreover, because cultural intelligence can be nurtured, service firms need to provide multicultural training programs for employees. For instance, service firms could educate their employees about how to communicate with culturally diverse customers, including by using appropriate language, gestures, tones, facial expressions, and sales skills for customers from specific cultures. Service firms should also encourage employees to consider cultural differences during intercultural interactions. Furthermore, service firms should be aware that the positive effect of cultural intelligence on adaptive sales behavior is due to a cognitive psychological process. That is, service employees with high cultural intelligence are likely to adopt customer viewpoints and understand their tacit needs and thereby practice adaptive sales behavior. Accordingly, managers should take appropriate actions to promote such cognitive processes.

\section{Limitations and Further Research Directions}

Despite making several important theoretical contributions that have significant managerial implications, the present study has several limitations. First, because we focused on salespeople at duty-free shops on Jeju Island, our findings may have limited generalizability. Future research should consider diverse service settings, such as hotels, airlines, and restaurants, as well as other geographic regions. Second, the concept of cultural intelligence has not yet been 
popularized in the service field. As such, there is a lack of standardized tools for measuring cultural intelligence from a service perspective. We measured cultural intelligence using a method adapted from Ang et al. (2007), which was developed by focusing on foreign employees working in cross-cultural work environments from an organizational management perspective. Future research should develop new measures that are specifically tailored to sales situations. Finally, all questionnaires were completed by salespeople, and the data therefore represent self-reports. This is useful in controlling for extraneous variables while exploring the relationship among cultural intelligence and outcome variables. However, the self-reported nature of the data means that salespeople may have overestimated their adaptive sales behavior. Thus, future research should address this methodological limitation by using alternate methods.

\section{References}

Ang, S., \& Van Dyne, L. (2008). Conceptualization of cultural intelligence: definition, distinctiveness, and nomological network. Handbook of Cultural Intelligence: Theory, Measurement, and Applications, 3-15.

Ang, S., Van Dyne, L., \& Koh, C. (2006). Personality correlates of the four-factor model of cultural intelligence. Group \& Organization Management, 31(1), 100-123.

Ang, S., Van Dyne, L., Koh, C., Ng, K. Y., Templer, K. J., Tay, C., \& Chandrasekar, N. A. (2007). Cultural intelligence: its measurement and effects on cultural judgment and decision making, cultural adaptation and task performance. Management and Organization Review, 3(3), 335-371.

Ashforth, B. E., \& Mael, F. (1989). Social identity theory and the organization. Academy of Management Review, 14(1), 20-39.

Baldauf, A., \& Cravens, D. W. (2002). The effect of moderators on the salesperson behavior performance and salesperson outcome performance and sales organization effectiveness relationships. European Journal of Marketing, 36(11-12), 1367-1388.

Batson, C. D., \& Shaw, L. L. (1991). Evidence for altruism: toward a pluralism of prosocial motives. Psychological Inquiry, 2(2), 107-122.

Berry, J. W., Poortinga, Y. H., Segall, M. H., \& Dasen, P. R. (1992). Cross-Cultural Psychology: Research and Applications. New York, NY: Cambridge University Press.

Bettencourt, L. A., Gwinner, K. P., \& Meuter, M. L. (2001). A comparison of attitude, personality, and knowledge predictors of service-oriented organizational citizenship behaviors. Journal of Applied Psychology, 86(1), 29-41.

Bloom, P. (2017). Empathy and its discontents. Trends in Cognitive Sciences, 21(1), 24-31.

Brislin, R., Worthley, R., \& Macnab, B. (2006). Cultural intelligence understanding behaviors that serve people's goals. Group \& Organization Management, 31(1), 4055.

Brislin, R. W. (1970). Back-translation for cross-cultural research. Journal of Cross-Cultural Psychology, 1(3), 185-216.

Chen, X. P., Liu, D., \& Portnoy, R. A. (2012). Multilevel investigation of motivational cultural intelligence, organizational diversity climate, and cultural sales: Evidence from U.S. real estate firms. Journal of Applied Psychology, 97(1), 93-106.

Crowne, K. A. (2009). The relationships among social intelligence, emotional intelligence and cultural intelligence. Organization Management Journal, 6(3), 148-163.

Davis, M. H. (1980). A multidimensional approach to individual differences in empathy. JSAS Catalog of Selected Documents in Psychology, 10, 85.

Delpechitre, D., \& Baker, D. S. (2017). Cross-cultural selling: examining the importance of cultural intelligence in sales education. Journal of Marketing Education, 39(2), 94-108.

Earley, P. C., \& Ang, S. (2003). Cultural Intelligence: Individual Interactions across Cultures. Standford, CA: Stanford University Press.

Fornell, C., \& Larcker, D. F. (1981). Evaluating structural equation models with unobservable variables and measurement error. Journal of Marketing Research, 18(1), 39-50.

Franke, G. R., \& Park, J. E. (2006). Salesperson adaptive sales behavior and customer orientation: a metaanalysis. Journal of Marketing Research, 43(4), 693702.

Gardner, H. (1985). Frames of mind: the theory of multiple intelligences. Quarterly Review of Biology, 4(3), 19-35.

Gaur, S. S., Sharma, P., Herjanto, H., \& Kingshott, R. (2017). Impact of frontline service employees' acculturation behaviors on customer satisfaction and commitment in intercultural service encounters. Journal of Service Theory and Practice, 27(6), 1105-1121.

Gerbing, D. W., \& Anderson, J. C. (1988). An updated paradigm for scale development incorporating unidimensionality and its assessment. Journal of Marketing Research, 25(2), 186-192.

Giacobbe, R. W., Jackson, D. W. Jr., Crosby, L. A., \& Bridges, C. M. (2006). A contingency approach to adaptive selling behavior and sales performance: selling situations and salesperson characteristics. Journal of 
Personal Selling \& Sales Management, 26(2), 115-142.

Groves, K. S., Feyerherm, A., \& Gu, M. (2015). Examining cultural intelligence and cross-cultural negotiation effectiveness. Journal of Management Education, 39(2), 209-246.

Hansen, J. D., Singh, T., \& Weilbaker, D. C. (2011). Cultural intelligence in cross-cultural selling: propositions and directions for future research. Journal of Personal Selling and Sales Management, 31(3), 243254.

Hogg, M. A., \& Terry, D. J. (2000). Social identity and selfcategorization processes in organizational contexts. Academy of Management Review, 5(1), 121-140.

Hu, L. T., \& Bentler, P. M. (1999). Cutoff criteria for fit indexes in covariance structure analysis: conventional criteria versus new alternatives. Structural Equation Modeling: A Multidisciplinary Journal, 6(1), 1-55.

Huff, K. C., Song, P., \& Gresch, E. B. (2014). Cultural intelligence, personality, and cross-cultural adjustment: a study of expatriates in Japan. International Journal of Intercultural Relations, 38(1), 151-157.

Itani, O. S., \& Inyang, A. E. (2015). The effects of empathy and listening of salespeople on relationship quality in the retail banking industry: the moderating role of felt stress. International Journal of Bank Marketing, 33(6), 692-716.

Jeon, S. S. (2001). A study on multiple intelligence theory and art educational implications. Journal of Sa Yang Art Education, 9, 73-112.

Joseph, D. L., \& Newman, D. A. (2010). Emotional intelligence: an integrative meta-analysis and cascading model. Journal of Applied Psychology, 95(1), 54-78.

Kerem, E., Fishman, N., \& Josselson, R. (2001). The experience of empathy in everyday relationships: cognitive and affective elements. Journal of Social and Personal Relationships, 18(5), 709-729.

Kim, S. H. (2006). The effect of cognitive and emotional empathy on emotional dissonance and prosocial behavior to customer. Journal of Korean Marketing Association, 21(2), 115-147.

Kim, S. H. (2014). Salespersons happiness and empathy for customers: an empirical study on influence of positive psychology. Journal of Channel and Retailing, 19(2), 27-64.

Kim, Y. K. (2015). A study on antecedents and consequences of empathy ability of service employee. Management and Information Systems Review, 34(1), 121-142.

Kong, L. L., Kim, H. G., \& Kim, Y. J. (2017). The moderating effects of salesperson's cultural intelligence in intercultural sales encounters. Journal of Distribution Science, 15(12), 85-94.

Lipps, T. (1907). The knowledge of aliens. Psychologische
Untersuchen, 1, 694-722.

Locander, D. A., Mulki, J. P., \& Weinberg, F. J. (2014). How do salespeople make decisions? the role of emotions and deliberation on adaptive selling, and the moderating role of intuition. Psychology \& Marketing, 31(31), 387-403.

Lorenz, M. P., Ramsey, J. R., Tariq, A., \& Morrel, D. L. (2017). Service excellence in the light of cultural diversity: The impact of metacognitive cultural intelligence. Journal of Service Theory and Practice, 27(2), 475-495.

Mayer, J. D., \& Salovey, P. (1993). The intelligence of emotional intelligence. Intelligence, 17(4), 433-442.

Mayer, J. D., Caruso, D. R., \& Salovey, P. (1999). Emotional intelligence meets traditional standards for an intelligence. Intelligence, 27(4), 267-298.

McBane, D. A. (1995). Empathy and the salesperson: a multidimensional perspective. Psychology \& Marketing, 12(4), 349-370.

Miller, K. I., Stiff, J. B., \& Ellis, B. H. (1988). Communication and empathy as precursors to burnout among human service workers. Communication Monographs, 55(3), 250-265.

Moon, T. (2010). Emotional intelligence correlates of the four-factor model of cultural intelligence. Journal of Managerial Psychology, 25(8), 876-898.

Sahin, F., \& Gürbüz, S. (2014). Cultural intelligence as a predictor of individuals' adaptive performance: a study in a multicultural environment. International Area Studies Review, 17(4), 394-413.

Solnet, D. (2006). Introducing employee social identification to customer satisfaction research: A hotel industry study. Journal of Service Theory and Practice, 16(6), 575-594.

Spiro, R. L., \& Weitz, B. A. (1990). Adaptive selling: conceptualization, measurement, and nomological validity. Journal of Marketing Research, 27(1), 61-69.

Sternberg, R. J. (2002). Reply to the book review on practical intelligence in everyday life. Intelligence, 30(1), 117-118.

Strayer, J. (1987). Affective and Cognitive Perspectives on Empathy. In N. Eisenberg \& J. Strayer (Eds.), Empathy and Its Development (pp. 218-244). New York, NY: Cambridge University Press.

Tajfel, H., \& Turner, J. (1979). An integrative theory of intergroup conflict. Social Psychology of Intergroup Relations, 33, 94-109.

Sharma, P., \& Wu, Z. (2015). Consumer ethnocentrism vs. intercultural competence as moderators in intercultural service encounters. Journal of Services Marketing, 29(2), 93-102.

Sharma, P., Tam, J. L., \& Kim, N. (2012). Intercultural service encounters (ICSE): an extended framework and 
empirical validation. Journal of Services Marketing, 26(7), 521-534.

Thorndike, R. L., \& Stein, S. (1937). An evaluation of the attempts to measure social intelligence. Psychological Bulletin, 34(5), 275-285.

Weitz, B. A., Sujan, H., \& Sujan, M. (1986). Knowledge, motivation, and adaptive behavior: a framework for improving selling effectiveness. Journal of Marketing, 50(4), 174-191.

Widmier, S. (2002). The effects of incentives and personality on salesperson's customer orientation. Industrial Marketing Management, 31(7), 609-615. 